\title{
Root-soil rotation stiffness of Norway spruce (Picea abies (L.) Karst) growing on subalpine forested slopes
}

\author{
M. J. Jonsson · A. Foetzki · M. Kalberer • \\ T. Lundström $\cdot$ W. Ammann $\cdot$ V. Stöckli
}

Received: 15 December 2005/ Accepted: 11 April 2006/Published online: 14 July 2006

(C) Springer Science+Business Media B.V. 2006

\begin{abstract}
Trees bend and break when exposed to external forces such as wind, rockfall, and avalanches. A common simplification when modelling the tree response to these forces is to simplify the system as a clamped beam which means that the stem deflection is related to the stem flexibility only. However, a certain part of the stem deflection originates from rotation of the root-soil plate. In this paper, we investigate this contribution to the overall stem deflection. Norway spruce (Picea abies (L.) Karst) trees were subjected to winching tests to analyse the anchorage mechanics of the tree. The tests were performed at two experimental sites with an average slope of 32 and $34^{\circ}$ and one site with a nearly flat ground in subalpine forests near Davos, Switzerland, during the vegetation periods of 2003 and 2004. The trees were pulled downslope with a winch and the applied force, stem base rotation, and the angle of the applied force relative to the stem were recorded. After the tree had fallen over, stem diameter and branch mass were measured for every meter segment. These data were used to model the tree in the finite element software ANSYS $^{\circledR}$, which was used for calculating the rotational stem base moment as
\end{abstract}

M. J. Jonsson $(\bowtie) \cdot A$. Foetzki · M. Kalberer ·

T. Lundström · W. Ammann · V. Stöckli

WSL Swiss Federal Institute for Snow and Avalanche

Research SLF, CH-7260 Davos, Switzerland

e-mail: jonsson@slf.ch a function of stem base rotation. The root-soil rotation stiffness $k_{\text {root }}$ was defined as the secant stiffness calculated at $0.5^{\circ}$ root-soil plate rotation. Young's modulus of elasticity $E$ of the stem was iteratively changed until the correct stem rotation was obtained. The best correlation between $k_{\text {root }}$ and different tree characteristics was the squared diameter at breast height, $\mathrm{DBH}^{2}$. Not incorporating the normal forces due to weight of the overhanging masses from crown and stem resulted in a maximum underestimation for $k_{\text {root }}$ of approximately $14 \%$. Thus, also the acting moment on the stem base will be underestimated causing the safety factor against uprooting to be overestimated.

Keywords Anchorage mechanics - Finite element method · Young's modulus of elasticity · Tree stability $\cdot$ Winching experiment

\section{Nomenclature}

$k_{\text {root }}$ root-soil rotation stiffness $(\mathrm{kN} \mathrm{m} / \mathrm{rad})$

$E \quad$ Young's modulus of elasticity (MPa)

$\mathrm{DBH}$ diameter at breast height $(\mathrm{m})$

$H_{\mathrm{t}} \quad$ total tree height $(\mathrm{m})$

$H_{\mathrm{f}} \quad$ height of applied force $(\mathrm{m})$

$H_{\mathrm{c}} \quad$ crown length $(\mathrm{m})$

$W_{\mathrm{t}} \quad$ total tree mass $(\mathrm{kg})$

$W_{\mathrm{c}} \quad$ crown mass $(\mathrm{kg})$

$F \quad$ applied force $(\mathrm{kN})$

$F_{\mathrm{h}} \quad$ horizontal force component $(\mathrm{kN})$

$F_{\mathrm{v}} \quad$ vertical force component $(\mathrm{kN})$ 
$\beta_{\mathrm{F}}$ measured angle of the applied force in relation to the horizontal plane $\left(^{\circ}\right)$

$\rho$ density of green wood $\left(\mathrm{kg} / \mathrm{m}^{3}\right)$

$M$ rotational stem base moment $(\mathrm{Nm})$

$\theta_{0} \quad$ extrapolated stem base rotation due to initial leaning of stem $\left(^{\circ}\right)$

$P \quad$ level of significance for the polynomial coefficients

\section{Introduction}

The root system is a crucial element for the growth and the stability of a tree. Its main functions are to provide the tree with water and nutrients and to prevent the tree from being overturned when exposed to forces resulting from wind, rockfall or avalanches. To predict the probability of uprooting for the root system, knowledge is required about the stem base moment as a function of stem base rotation, the ultimate rotational moment and the acting bending moment derived from the forces applied to the tree. The ultimate rotational moment of the root system depends on four components: (1) the mass of the root-soil plate, (2) the shear strength of the soil, (3) the resistance to failure in tension for tree roots on the windward side and (4) the resistance to bending and shear of the tree roots on the leeside (Blackwell et al. 1990). Coutts (1986) investigated the relationship between these four components for Sitka spruce (Picea sitchensis (Bong.) Carr) and concluded that the major contributions to the ultimate rotational moment comes from the windward roots and the mass of the root-soil plate. To investigate the ultimate failure capacity of trees, winching experiments were carried out by a number of research teams (Fraser and Gardiner 1967; Crook and Ennos 1996; Moore 2000; Peltola et al. 2000). Winching experiments were also performed on trees growing on slopes (Achim et al. 2003; Nicoll et al. 2005), as well as on dead trees (Ammann 2005).

Trees bend and eventually fail when exposed to external forces such as wind, rockfall, and avalanches. A common simplification when modelling the tree response to these forces is to simplify the system to a clamped beam which means that the stem deflection is related to the stem flexibility only. However, a certain part of the stem deflection originates from rotation of the root-soil plate (Neild and Wood 1999). This contribution can be quantified by means of the root-soil rotation stiffness $k_{\text {root }}$. The importance of taking $k_{\text {root }}$ into account when calculating the tree response to wind is highlighted by Neild and Wood (1999). A more accurate prediction of the stem's bending line, the natural frequencies of the tree as well as Young's modulus of elasticity $E$ (Yang et al. 2004) for the tree stem are obtained when including $k_{\text {root }}$ the mechanical model of the tree. In addition to the above mentioned reasons for including $k_{\text {root }}$ also a strong correlation with the ultimate rotational moment of the root system can be expected (Brudi and Wassenaer 2001). Thus, knowing $k_{\text {root }}$, no winching experiments until failure of the root-soil system have to be conducted. However, only a few studies have been carried out to determine $k_{\text {root }}$ (Fraser and Gardiner 1967; Neild and Wood 1999).

Norway spruce (Picea abies (L). Karst) is the most common species in European subalpine forests (Ellenberg 1996). Of the total protection forests in Switzerland against natural hazards (rockfall and avalanches) around 56\% are represented by spruce-fir forests and spruce, larch and stone-pine forests (Brassel and Brändli 1999). To accurate predict the mechanical behavior of Norway spruce trees exposed to external forces 23 Norway spruce trees growing on slopes in a subalpine forest were tested in winching experiments to quantify the root-soil rotation stiffness $k_{\text {root }}$ for the root system and Young's modulus of elasticity $E$ for the tree stem.

\section{Materials and methods}

\section{Experimental sites}

The winching experiments were performed at three different experimental sites (Table 1) in subalpine forests near Davos, Switzerland, during the vegetation periods (May/June-September) of 2003 and 2004. Two experimental sites are located 
Table 1 Average slope angle, location, aspect, altitude and number of tests for all three experimental sites

\begin{tabular}{llllllc}
\hline Site & Slope angle & Latitude & Longitude & Aspect & Altitude (m) & No. of tests \\
\hline Mattawald (1) & $34^{\circ}$ & $9^{\circ} 50^{\prime} 24^{\prime \prime}$ & $46^{\circ} 47^{\prime} 42^{\prime \prime}$ & NW & 1700 & 7 \\
Brüchwald (2) & $32^{\circ}$ & $9^{\circ} 48^{\prime} 12^{\prime \prime}$ & $46^{\circ} 46^{\prime} 59^{\prime \prime}$ & SE & 1800 & 13 \\
Seehornwald (3) & $10^{\circ}$ & $9^{\circ} 51^{\prime} 7^{\prime \prime}$ & $46^{\circ} 48^{\prime} 55^{\prime \prime}$ & SW & 1636 & 3 \\
\hline
\end{tabular}

on slopes and one on nearly flat ground (Table 1). The vegetation type is a Norway spruce (Picea abies (L.) Karst.) forest with single European larch (Larix decidua L.). All three forest stands are moderately managed. The ground is covered by a mixture of grass (Calamagrostis villosa (Chaix) Gmel.) and dwarfshrubs, e.g., bilberry (Vaccinium myrtillus). Davos is located in the central alps in the northeast part of the canton Grisons at an altitude of $1560 \mathrm{~m}$. The surroundings of Davos have an alpine topography with peaks reaching up to $3100 \mathrm{~m}$. The climate is characterised by a mean annual precipitation of $1082 \mathrm{~mm}$ (Jan $74 \mathrm{~mm}$, Aug $146 \mathrm{~mm}$ ) of which approximately $40 \%$ is snow and an average daily temperature of $2.8^{\circ} \mathrm{C}\left(\mathrm{Jan}-5.3{ }^{\circ} \mathrm{C}\right.$, Aug $10.8^{\circ} \mathrm{C}$ ), evaluated between 1961 and 1990 (Meteoschweiz 2004).

The trees were exposed to moderate wind and neither rockfall and avalanches, due to the fact that all test sites were located inside the forest stand. The major wind direction in the valley of Davos is north to south with the strongest winds coming from north (Meteoschweiz 2004). The trees on the three test sites were all mature trees with a mean diameter at breast height DBH $( \pm$ one standard error) $32.0 \pm 14,40.0 \pm 15$ and $26.0 \pm 10 \mathrm{~cm}$, and dominant height of $33.0,35.0$ and $28.0 \mathrm{~m}$ respectively. The stand density for respective test site was approximately 450, 320 and 580 trees per hectare. The soil at all experimental sites is a highly acid podzol (well graded gravel with silt and sand) with a good permeability and a high proportion of stones. At experimental site 3 (Table 1), preliminary tests were conducted to optimise the test set-up.

Test methods

Two different test set-ups were used for the winching experiments on five trees growing on test site 2 . The first test-set up was used for winching experiments and the second test set-up was used to perform swaying experiments on the trees (M.J. Jonsson et al., submitted). Recording the data when getting the tree into release position before the swaying experiments enabled that this test set-up could also be used to evaluate the rootsoil rotation stiffness $k_{\text {root }}$. Thus, on these five trees two successive tests were performed.

The two test-setups used were similar to those used by e.g. Fraser and Gardiner (1967); Peltola et al. (2000); Nicoll et al. (2005), however, adopted for our purpose. For the first test set-up, the rotations of the tree stem at 2, 5 and $20 \%$ of the total tree height $H_{\mathrm{t}}$ were recorded. The height of applied force, $H_{\mathrm{f}}$, was $20 \%$ of $H_{\mathrm{t}}$. For the second test set-up, the rotation of the tree stem was measured at 2,20,53 and $75 \%$ of $H_{\mathrm{t}}$, and $H_{\mathrm{f}}$ was changed to $53 \%$ of $H_{\mathrm{t}}$. The angle of the applied force $\beta_{\mathrm{F}}$ was measured when the pulling cable was stretched (Fig. 1) using an portable inclinometer. To record the stem rotation at 2 and $5 \%$ of $H_{\mathrm{t}}$, an inclinometer (PMP-2.5 TZL-A-SW2 Pewatron AG, Wallisellen/Zürich, Switzerland) with a range of $\pm 2.5^{\circ}$ and a precision of $\pm 0.0375^{\circ}$ was used. For the recording of the stem rotation at 20,53 and $75 \%$ of $H_{t}$, inclinometers (PMP-20 TZL-A-SW2 Pewatron AG) with a range of $\pm 20^{\circ}$ and a precision of $\pm 0.3^{\circ}$ were used. The applied winching force was measured with a load cell (MTS Tensile Force Sensor, Type 85081-6100-V0000C0, 944860, Meßtechnik Schaffhausen GmbH, Neuhausen, Switzerland) with a maximum capacity of $100 \mathrm{kN}$ and a precision of $\pm 0.2 \mathrm{kN}$. The sampling rate was $5 \mathrm{~Hz}$ for the first and $20 \mathrm{~Hz}$ for the second test set-up. To record the stem base rotation without the contribution from the stem bending deformation the sensor was mounted as low as possible on the tree stem. To avoid difficulties when attaching this sensor to the tree stem it was mounted above the buttress area and its irregularities and defined as the measured rotation at $2 \%$ of $H_{\mathrm{t}}$. The stem section below was considered to be rigid. The trees were winched to 
Fig. 1 Overview of the test set-up used for the winching experiments. $H_{\mathrm{t}}=$ total tree height, $H_{\mathrm{f}}=$ height of applied force, $F$ = applied force, $F_{\mathrm{h}}=$ horizontal force component, $F_{\mathrm{v}}=$ vertical force component, $\beta_{\mathrm{F}}=$ angle of the applied force

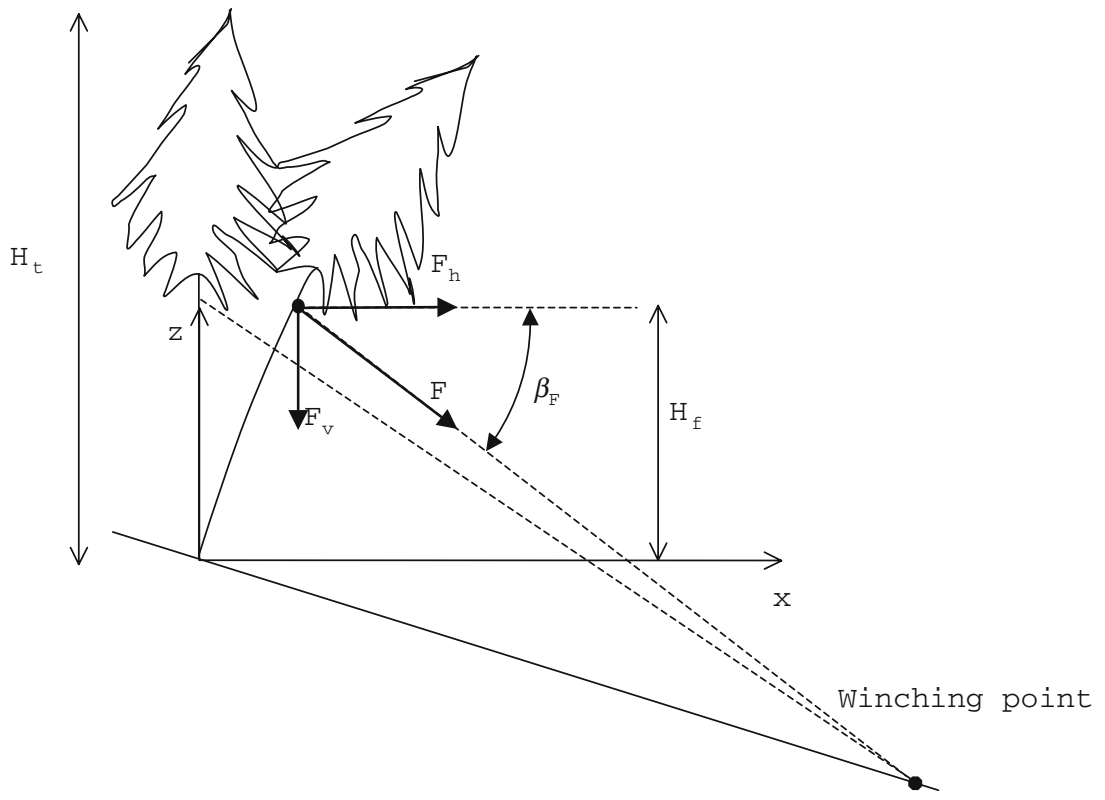

The point of rotation of the root-soil plate was not quantified during the winching experiments. To simplify the calculation it was therefore assumed that the tree rotated around the point where the stem centreline intersects with the surface of the soil, even though it is known that the tree rotates around the leeward side of the tree trunk (Coutts 1986; Nicoll et al. 2005). The recorded stem base rotation was applied as a boundary condition at the stem base in the FEM model. For the FEM calculations the tree stem was assumed to be straight, the density of green wood and Poisson's ratio were assumed to be $\rho=850 \mathrm{~kg} / \mathrm{m}^{3}$ (unpublished data SLF) and $v=0.26$ (Kollmann and Côté 1968), respectively. The tree material was assumed to be isotropic and constant over both cross-section and height (Milne and Blackburn 1989; Milne 1991). To calculate the rotational stem base moment large deflection theory was used. This means that the extra moment from the normal forces due to overhanging tree stem and crown (branches) were taken into account. For every tree the rotational stem base moment was calculated in 100 load steps.

The rotation of the root-soil plate at a specific time can be expressed as follows:

$\theta_{i}=\theta_{0}+\frac{M_{i}}{k_{i}}$ 
where $\theta_{0}$ is the initial rotation of the root-soil plate and $k_{i}$ is the secant stiffness corresponding to the stem base moment $M_{i}$. Solving for $k_{i}$ gives the following relationship:

$k_{i}=\frac{M_{i}}{\theta_{i}-\theta_{0}}$

To estimate $\theta_{0}$ a linear elastic interval was introduced between 0 and $0.1^{\circ}$ stem base rotation $\theta_{i}$, which is lower than the elastic interval of $0.25^{\circ}$ suggested by (Brudi and Wassenaer (2001). Using the least square method to solve the equation system, $\theta_{0}$ and the initial stiffness for this assumed linear elastic interval could be calculated. To estimate $k_{i}$ the following methodology was applied:

- the recorded rotations and applied force data were averaged over one second to smooth the data.

- the Young's modulus of elasticity $E$ for the stem was iteratively changed until measured and calculated rotation for all the inclinometers differed less than $5 \%$.

- the rotational stem base moment $M_{i}$ was plotted against the stem base rotation $\theta_{i}$, and the least square method was used to calculate $\theta_{0}$ (Fig. 2).

- the secant stiffness was calculated according to Eq. 2 for every measured value of $\theta_{i}$.

To compare the stiffness between all trees the calculated secant stiffness $k_{i}$ for $0.5^{\circ}$ stem base rotation was used. This value was selected because all trees were winched to at least $0.5^{\circ}$ stem

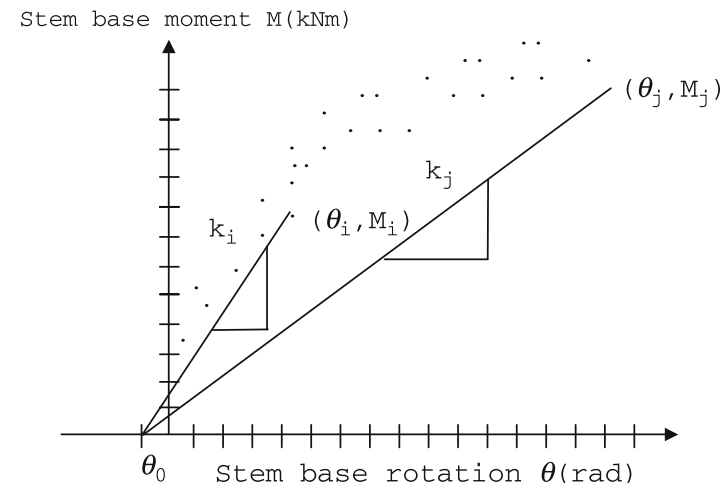

Fig. 2 Overview of the rotational stem base moment versus rotation at stem base $\theta, \theta_{0}$ extrapolated stem base rotation due to initial leaning of stem base rotation which then allowed a comparison between all the trees. The calculated secant stiffness for $0.5^{\circ}$ rotation of the root-soil plate is referred to as the root-soil rotation stiffness and noted as $k_{\text {root }}$.

The data were investigated with the commercial software S-plus ${ }^{\circledR}$ (Insightful Corporation, Seattle, Washington, USA) using regression analysis. The regressions were forced to intercept with the origin as this is physically meaningful. When DBH, $H_{\mathrm{t}}$ or stem masses etc. are zero, $k_{\text {root }}$ and $E$ must be zero as well. The regression analysis was checked regarding the level of significance for polynomial terms using the $F$-test, and the sum of squared errors, $R^{2}$. A relation between evaluated results were considered useful if $R^{2}>0.5$, and the polynomial coefficients, $p_{i}$, meaningful if their level of significance $P<0.05$.

To investigate the sensitivity of $k_{\text {root }}$ to the input parameters, three trees from experimental site 2 were selected (Table 2). For these trees the crown mass, Young's modulus of elasticity and density were all changed with $\pm 25 \%$ and the influence on $k_{\text {root }}$ was analysed.

\section{Results}

By iteratively changing Young's modulus of elasticity $E$ for the tree stem until the measured and calculated stem rotation corresponded, it was possible to estimate the elasticity for the tree stem (Fig. 3).

For all trees the secant stiffness decreased as the stem base rotation increased (Fig. 4).

When performing two successional tests, the calculated secant stiffness was always lower for the second test (Table 3). This is not only valid for a specific point, but for the whole recorded

Table 2 Geometric properties of the trees growing in experimental site 2 , used in the sensitivity analysis of the root-soil rotation stiffness $k_{\text {root }}, H_{\mathrm{t}}=$ total tree height, $H_{\mathrm{c}}=$ crown length, $W_{\mathrm{t}}=$ total tree mass and $W_{\mathrm{c}}=$ crown mass

\begin{tabular}{lllll}
\hline Tree no. & $H_{\mathrm{t}}(\mathrm{m})$ & $H_{\mathrm{c}}(\mathrm{m})$ & $W_{\mathrm{c}}(\mathrm{kg})$ & $W_{\mathrm{t}}(\mathrm{kg})$ \\
\hline 2 & 32.9 & 6.1 & 505 & 3031 \\
4 & 33.5 & 9.25 & 283 & 3408 \\
5 & 27.9 & 6.2 & 284 & 1698 \\
\hline
\end{tabular}




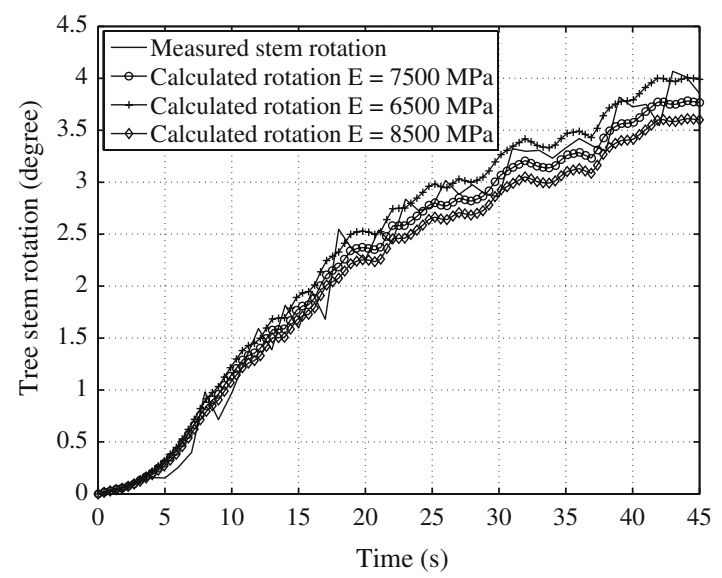

Fig. 3 Calculated stem rotation at $20 \%$ of total tree height $H_{\mathrm{t}}$ for tree 1 experimental site 2 . The time indicate the total time for the winching experiment

range (Fig. 5). The decrease in $k_{\text {root }}$ calculated at $0.5^{\circ}$ rotation of the root-soil plate between the first and second test was on average 30.9\% $(n=5)$.

The measured rotation of the root-soil plate sometimes indicated a residual rotation at the tree base after the force was released. Due to this finding and the difference in secant stiffness between two successional test for the same tree, only the first performed test was included in the future statistical analysis. This means that tests with $H_{\mathrm{f}}$ at $20 \%$ of $H_{\mathrm{t}}$ for tree No. 1, 2, 4, 5 and 3.b from experimental site 2 were excluded from the statistical analysis (Table 3).

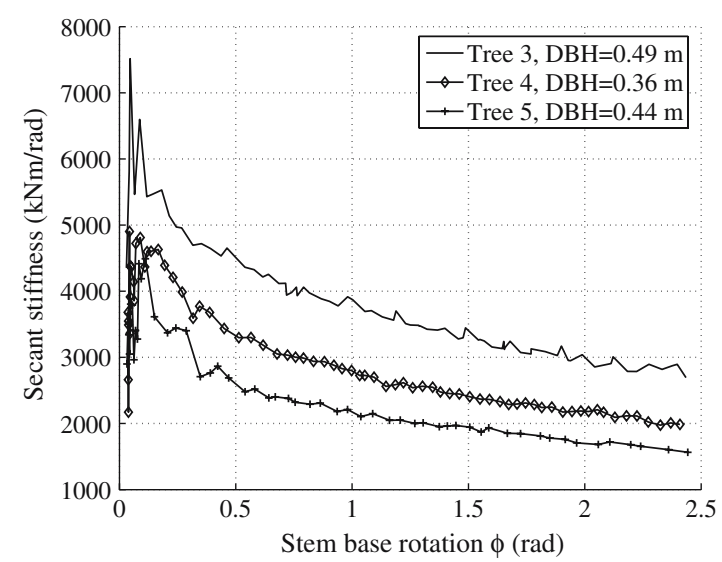

Fig. 4 Calculated secant stiffness as a function of stem base rotation $\theta$ for tree no. 3, 4 and 5 at experimental site 1. Tree 4 has a smaller diameter at breast height $\mathrm{DBH}$ but a larger stiffness compared to tree 5

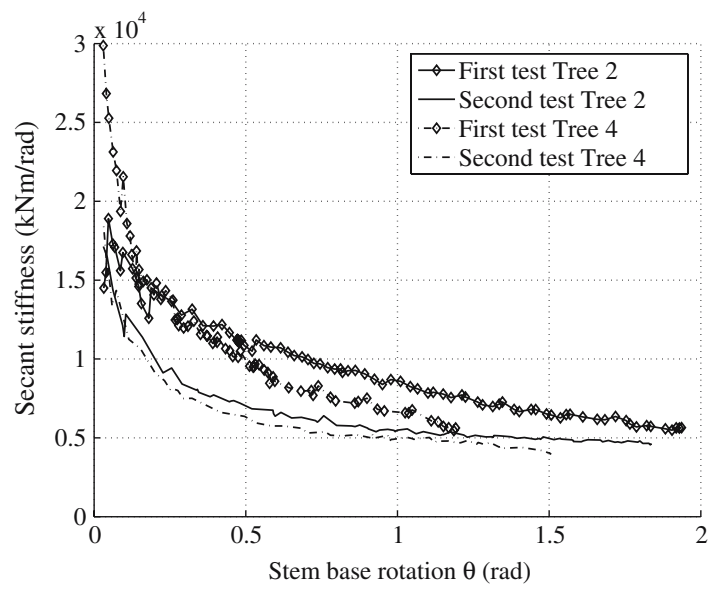

Fig. 5 Secant stiffness as a function of stem base rotation $\theta$ for two trees tested twice, the trees are from experimental site 2 . The secant stiffness is lower for both trees during the second experiment

No statistical investigation was made regarding the difference in stiffness due to slope exposition, because of the low number of tests on the sites 1 and 3. For the remaining 18 tests, the model $k_{\text {root }}=p_{1} \cdot \mathrm{DBH}^{2}$ was best fitted to the data. Including all tests gave a significant value of $p_{1}$. One outlier was observed and identified as tree 3 , experimental site 3 . The $E$ for this tree was almost three times higher than the average value for all trees. Although we found no visual damages on this tree e.g. rockfall scars or rot we excluded it from the statistical analysis due to possibilities of unobserved damage. For $k_{\text {root }}$ this resulted in $p_{1}=28427$ and $P<0.001$ with $R^{2}=0.64$ (Fig. 6).

No correlation for $E$ with tree characteristics such as DBH and $H_{\mathrm{t}}$ were found when including all trees in the statistical analysis. Therefore, only the mean value, $\bar{E}=8289 \mathrm{MPa}$, and the standard deviation, $\sigma=3602 \mathrm{MPa}$ were calculated. Excluding tree 3 at experimental site 3 with the same motivation as above and calculating mean and standard deviation resulted in $\bar{E}=7634 \mathrm{MPa}$, $\sigma=1803 \mathrm{MPa}$.

To investigate the sensitivity of $k_{\text {root }}$ to the normal forces due to overhanging stem and crown mass, three trees were selected for further investigations. Excluding the crown mass the maximum underestimation of $k_{\text {root }}$ were $8.1 \%$ (Table 4 ). Excluding the stem weight by setting its density to $1 \mathrm{~kg} / \mathrm{m}^{3}$ and the crown mass to zero resulted in a 
Table 3 Root-soil rotation stiffness $k_{\text {root }}$ and Young's modulus of elasticity $E$ for all the trees, $\mathrm{DBH}=$ diameter at breast height $H_{\mathrm{t}}=$ total tree height $H_{\mathrm{f}}=$ height of applied force. For tree 3 at experimental site 2 , two tests were performed with the same $H_{\mathrm{f}}$, test 3 .a is included in the analysis

\begin{tabular}{lllllll}
\hline Experimental site & Tree no. & DBH $(\mathrm{m})$ & $H_{\mathrm{t}}(\mathrm{m})$ & $H_{\mathrm{f}}(\%)$ & $E(\mathrm{MPa})$ & $k_{\text {root }}(\mathrm{kN} \mathrm{m} / \mathrm{rad})$ \\
\hline 1 & 1 & 0.40 & 31.25 & 20 & 6550 & 5267 \\
1 & 2 & 0.39 & 34.1 & 20 & 6900 & 5087 \\
1 & 3 & 0.49 & 33.3 & 20 & 6000 & 4510 \\
1 & 4 & 0.36 & 31.4 & 20 & 8300 & 3327 \\
1 & 5 & 0.44 & 30.0 & 20 & 7800 & 2599 \\
1 & 6 & 0.48 & 33.0 & 20 & 8500 & 6772 \\
1 & 7 & 0.43 & 30.0 & 20 & 6800 & 4212 \\
2 & 1 & 0.35 & 25.6 & 20 & 7500 & 2026 \\
2 & 1 & 0.35 & 25.6 & 53 & 9000 & 2562 \\
2 & 2 & 0.48 & 32.9 & 20 & 5350 & 7027 \\
2 & 2 & 0.48 & 32.9 & 53 & 5600 & 10785 \\
2 & $3 . \mathrm{a}$ & 0.44 & 29.9 & 53 & 7300 & 5033 \\
2 & $3 . \mathrm{b}$ & 0.44 & 29.9 & 53 & 7450 & 3179 \\
2 & 4 & 0.58 & 33.5 & 20 & 5800 & 6318 \\
2 & 4 & 0.58 & 33.5 & 53 & 7000 & 9925 \\
2 & 5 & 0.43 & 27.9 & 20 & 5500 & 2853 \\
2 & 5 & 0.43 & 27.9 & 53 & 8000 & 2831 \\
2 & 6 & 0.22 & 20.7 & 20 & 13500 & 1589 \\
2 & 8 & 0.35 & 25.4 & 20 & 8500 & 2308 \\
2 & 9 & 0.50 & 34.9 & 20 & 7600 & 8500 \\
3 & 3 & 0.33 & 26.0 & 20 & 22700 & 9072 \\
3 & 4 & 0.37 & 27.0 & 20 & 9500 & 5170 \\
3 & 5 & 0.29 & 27.0 & 20 & 9500 & 2450 \\
\hline
\end{tabular}

underestimation of $k_{\text {root }}$ by $19.6,9.7$ and $13.5 \%$, respectively (Table 4). Comparing these results with the results obtained when only the crown mass is removed indicates that the contribution of the overhanging stem is about $11.6,7.5$ and $8.0 \%$, respectively. A change of $\pm 25 \%$ in $E$ and the stem density resulted in a maximum increase of

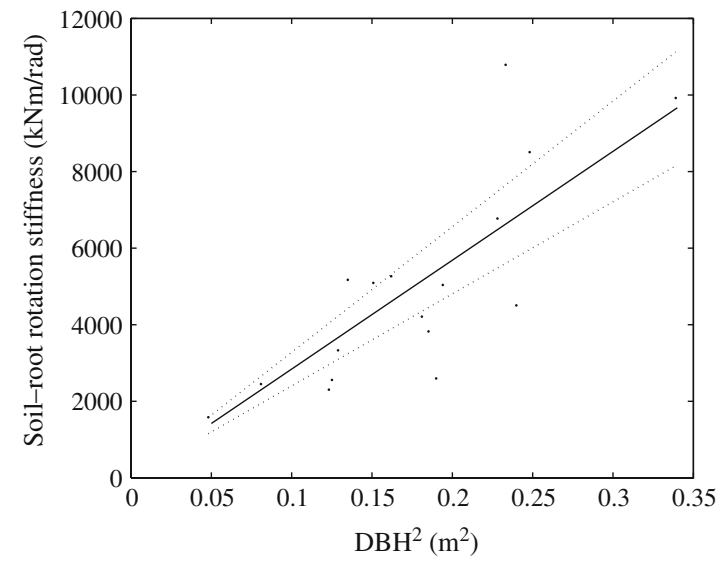

Fig. 6 Relationship between root-soil rotation stiffness $k_{\text {root }}$ and diameter at breast hight squared $\mathrm{DBH}^{2}$ for the 17 tests included in the regression analysis, $k_{\text {root }}=p_{1} \cdot D B H^{2}$, $p_{1}=28427$ and $R^{2}=0.64$. Upper and lower dotted lines shows limits for the $95 \%$ confidence interval
$9.7 \%$ and a maximum decrease of $4.8 \%$ for $k_{\text {root }}$ (Table 4).

\section{Discussion}

Analysis method and test set-up

To accurate predict the mechanical behavior of Norway spruce trees growing on slopes in a subalpine forest winching experiments were conducted to quantify the behavior of the rootsoil rotation stiffness and Young's modulus of elasticity $E$ for the tree stem. The influence of the normal forces due to the overhanging crown mass, stem and the vertical force component can easily be included when using a commercial finite element software. These are factors that should be included in the analysis when evaluating tree winching experiments. Neglecting this contribution will result in an underestimation of $E$ for the stem and a less precise prediction of the stem bending axis (Neild and Wood 1999; Peltola et al. 2000). We also showed that neglecting the normal forces caused by the overhanging stem and tree crown resulted in a maximum underestimation of the root-soil rotation stiffness $k_{\text {root }}$ with 
Table 4 Sensitivity in the root-soil rotation stiffness $k_{\text {root }}$ when changing Young's modulus of elasticity $E$, the density of green wood $\rho$ and the crown mass $W_{\mathrm{c}}$ for trees listed in Table 2

\begin{tabular}{|c|c|c|c|c|}
\hline Tree no. & $E(\mathrm{MPa})$ & $\rho\left(\mathrm{kg} / \mathrm{m}^{3}\right)$ & $k_{\text {root }}(\mathrm{kNm} / \mathrm{rad})$ & $\Delta k_{\text {root }}(\%)$ \\
\hline \multicolumn{5}{|c|}{ No crown mass } \\
\hline 2 & 5600 & 850 & 9918 & -8.1 \\
\hline 4 & 7000 & 850 & 9708 & -2.2 \\
\hline 5 & 8000 & 850 & 3622 & -5.5 \\
\hline \multicolumn{5}{|c|}{ No overhanging stem and crown mass } \\
\hline 2 & 5600 & 1 & 8671 & -19.6 \\
\hline 4 & 7000 & 1 & 8960 & -9.7 \\
\hline 5 & 8000 & 1 & 3315 & -13.5 \\
\hline \multicolumn{5}{|c|}{ Change in Young's modulus of elasticity $\pm 25 \%$} \\
\hline 2 & 7000 & 850 & 10267 & -4.8 \\
\hline 2 & 4200 & 850 & 11833 & +9.7 \\
\hline 4 & 8750 & 850 & 9761 & -1.7 \\
\hline 4 & 5250 & 850 & 10218 & +3.0 \\
\hline 5 & 10000 & 850 & 3730 & -2.6 \\
\hline 5 & 6000 & 850 & 4017 & +4.9 \\
\hline \multicolumn{5}{|c|}{ Change in stem density $\pm 25 \%$} \\
\hline 2 & 5600 & 1062 & 11239 & +4.2 \\
\hline 2 & 5600 & 637 & 10371 & -3.8 \\
\hline 4 & 7000 & 1062 & 10137 & +2.1 \\
\hline 4 & 7000 & 637 & 9721 & -2.1 \\
\hline 5 & 8000 & 1062 & 3924 & +2.4 \\
\hline 5 & 8000 & 637 & 3740 & -2.4 \\
\hline
\end{tabular}

approximately $14 \%$ (Table 4). This is in accordance with the values proposed by Peltola et al. (2000), who calculated the rotational stem base moment to be underestimated by $5-20 \%$, depending upon tree size. Thus, the acting moment on the stem base will be underestimated causing the safety factor against uprooting to be overestimated.

\section{Root-soil rotation stiffness $k_{\text {root }}$}

Many mechanical models have been developed to analyze wind interaction with trees (Saunderson et al. 1999; Peltola et al. 1999; Gardiner et al. 2000). However, a common assumption is to model the root-soil system with no flexibility, even though it is known that a better prediction of the bending line (Neild and Wood 1999; Yang et al. 2004), and thus the acting moment of the stem base is obtained. The reason for not including the flexibility is believed to be mostly due to lack of quantitative information for the moment versus stem base rotation relation. However, including the flexibility does not only improve the prediction of the tree's behavior with wind interaction. All transient processes such as rock impact on trees and avalanche interaction with trees can be much better understood.

The evaluation routine proposed here defines $k_{\text {root }}$ as a function of stem base rotation. When defining $k_{\text {root }}$ as not constant, the question arises as to which value should be used. This can be answered with measurements of the stem base rotation during specific wind actions. We suggest using values corresponding to the most frequent rotation at the stem base during a certain wind speed. It has been shown that the ultimate rotational moment for the stem base changes only slightly in different directions to the slope (Achim et al. 2003). From these results we suggest the use of the same value of $k_{\text {root }}$ for all the directions until quantitative data exist about the behaviour of the root-soil system in all four directions of the slope.

It was also observed that the secant stiffness decreased with increasing rotation. This decrease was observed from the very beginning of the results (Fig. 4). In case of an elastic interval of $0.25^{\circ}$ suggested by Brudi and Wassenaer (2001) no decrease in $k_{\text {root }}$ would be observed and a constant value would be found. Therefore, the obtained results indicate that the elastic interval is very small, and might not even exist at all. Five tests 
were carried out to investigate whether there is a difference in $k_{\text {root }}$ when performing two successional tests. A difference between these tests was always observed (Table 3, Fig. 5). This might originate from the fact that the plastic part of the deformation curve in the root-soil plate is reached. Even at a small inclination $k_{\text {root }}$ decreases when two successive tests are done. This could indicate that using the method suggested by Brudi and Wassenaer (2001) to investigate the tree stability the tested trees are not nondestructive tested and the residual ultimate rotational moment for the root-system might be overestimated. However, the tests were conducted during the same day and it must be further investigated to see whether the same results can be expected after more days and weeks, as this would give information about the healing process of the root-soil system.

Analysing the stem base rotation shows a residual rotation of the root-soil plate when the force is released. This supports the idea that the deformation of the root-soil plate enters the plastic range. The reason for this deformation might be deformation (damages) in the soil which leads to a redistribution of the soil material, or damage to the fine roots or a combinations of both. Coutts (1983) performed winching experiments on Sitka spruce (Picea sitchensis (Bong.) Carr) trees (34 year old co-dominant trees with a mean height of $20 \mathrm{~m}$ and mean DBH of $21 \mathrm{~cm}$ ) and recorded the breakage of roots/soil using buried microphones. On the windward side of the root-soil plate an upward movement was observed and sequential breakage of roots/soil were observed at approximately $0.5-1^{\circ}$ rotation at stem base. Another possible method to reveal which of these processes that are responsible for the residual rotation would be to investigate the changes in sapflow pattern during winching experiments on trees. Such investigations were performed on Maritime Pine (Pinus pinaster Ait) and oak (Quercus petraea) trees winched up to $10^{\circ}$ inclination (measured at the cable attachment point $3.6 \mathrm{~m}$. No information is given about the stem base rotation.) (Stokes et al. 2000). During the experiments a decrease in sapflow was observed only in the oak tree. The suggested explanation was stretching and compression of the longitudinal wood cells and thereby a tem- porarily redistribution of the sapflow. However, the tested trees were small $\mathrm{DBH}=13.1 \mathrm{~cm}$ and it is known that smaller trees are much more elastic and the effect of root/soil breakage might not have been observed. Thus, to reveal if the major process is breakage of the roots or the soil it is suggested that sapflow measurements are performed on larger trees in combination with carefully monitoring of the of the stem base rotation, or monitoring of midterm reaction of trees such as growth performance.

Because of annual variations in the soil water content, soil shear strength and cohesion forces between soil and roots, a variation of the ultimate rotational moment for the root system can be observed (Crook and Ennos 1996). The ultimate rotational moment and $k_{\text {root }}$ are closely connected which indicate that $k_{\text {root }}$ also changes with annual variations. Not only the soil properties effect $k_{\text {root }}$. The size of the root-soil plate, root architecture and the root-cross sectional area effect the ultimate rotational moment. These properties then effect the mass of the root-soil plate as well as the point of rotation for the a tree, factors that both increase the ultimate rotational moment at the stem base as well as $k_{\text {root }}$ (Coutts 1986; Blackwell et al. 1990; Bolkenius 2001).

Modulus of elasticity of the stem $E$

A common method used to obtain Young's modulus of elasticity $E$ for the tree stem in bending is to iteratively chang its value until the measured and calculated stem bending axis agree (Milne and Blackburn 1989; Milne 1991). We have in this paper shown that it is also possible to estimate $E$ when iteratively change its value until measured and calculated stem rotations correspond (Fig. 3). Comparing the obtained results with those from Peltola et al. (2000) (boreal areas) and Bruchert et al. (2000) (montane areas) shows that the $E$ are in the same order of magnitude.

The calculated value of $E$ for tree 3 at experimental site 3 is almost three times higher than the calculated average value for all trees. Also the $k_{\text {root }}$ is much higher for this tree (Table 3 ). The experimental site 3 was mainly used for tuning the test set-up. The high value of both 
$E$ and $k_{\text {root }}$ could indicate a problem with the test set-up. Studying the root architecture of this tree a large root-buttress was observed. Furthermore, this tree was growing on a small knoll exposed to wind. Both factors that might contribute to an increased stability. However, the root system showed an irregular root distribution with only two big lateral roots and the root-soil plate was smaller than for other trees with the same DBH, factors that lead to a lower stability.

\section{Conclusions}

- To iteratively change Young's modulus of elasticity $E$ for the stem until measured and calculated rotation for all the inclinometers correspond can be used to estimate the modulus of elasticity.

- Using the full power of a finite element code makes it possible to include the vertical forces due to the overhanging mass from stem and crown. Neglecting these two factors resulted in an underestimation of $k_{\text {root }}$ by up to $14 \%$.

- To use this data for predicting the critical wind speeds for a tree to overturn, knowledge is required about the root-soil rotation stiffness $k_{\text {root }}$ in all four directions of the slope as well as the rotation at stem base during certain wind speeds. With the data now available the exposure of a tree to downslope forces such as rockfall and avalanches can be more accurately modelled. However, further research must be done to quantify the behaviour of the root-soil system in all four directions to the slope.

- The elastic interval of $0.25^{\circ}$ rotation of the root-soil plate could not be verified, in this investigation no elastic interval was found for the rotation of the root-soil plate.

- The measured rotation of the root-soil plate sometimes indicated a residual rotation at the tree base after the force was released. Where this remaining deformation originates from must be further investigated.

Acknowledgements This study was supported by the Board of the Swiss Federal Institutes of Technology. We thank the landowners of the experimental sites for allowing us to perform the experiments, "Forstwerkhof Davos" for providing useful help during the fieldwork, Holger Simon for conducting the field experiments, Prof. Dr.
Alessandro Dazio (Institut für Baustatik und Konstruktion ETH-Zurich) and the anonymous reviewers of this paper.

\section{References}

Achim A, Nicoll B, Mochan S, Gardiner B (2003) Wind stability of trees on slopes. In: Ruck B, Kottmeier C, Mattheck C, Quine C, Wilhelm G (eds) International conference wind effects on trees. Laboratory for Building- and Environmental Aerodynamics, Inst. for Hydromechanics, University of Karlsruhe, Germany, pp 231-237

Ammann M (2005) Abgestorbene Bäume: Mechanische Eigenschaften und Schutzwirkung gegen Naturgefahren. Holzforschung Schweiz 1:4-5

ANSYS (2002) ANSYS, Inc. theory reference, verison 7.0, Canonsburg, USA

Blackwell PG, Rennolls K, Coutts MP (1990) A root anchorage model for shallowly rooted Sitka Spruce. Forestry 63:73-91

Bolkenius D (2001) Zur Wurtzelausbildung von Fichte (Picea abies L. [Karst] und wei $\beta$ banne (Abies alba Mill.) in gleich- und ungleichhaltrigen Bestände. Berichte Freiburger Forstliche Forschung Heft, p 35

Brassel P, Brändli UB (1999) Schweizerisches Landesforstinventar. Ergebnisse der Zweitaufnahme 1993-1995. Paul Haupt, Bern Stuttgart Wien, pp 442

Brüchert F, Becker G, Speck T (2000) The mechanics of Norway spruce [Picea abies (L.) Karst]: mechanical properties of standing trees from different thinning regimes. Forest Ecol Manag 135:45-62

Brudi E, Wassenaer PV (2001) Trees and statics: nondestructive failure analysis. In: Thomas ES, Kim DK (eds) Tree structure and mechanics conference proceedings: how trees stand up and fall down. International Soc. of Arboriculture, pp 53-69

Coutts MP (1983) Root architecture and tree stability. Plant Soil 71:171-188

Coutts MP (1986) Components of tree stability in Sitka Spruce on peaty gley soil. Forestry 59:173-197

Crook MJ, Ennos AR (1996) The anchorage mechanics of deep rooted larch, Larix europea $\mathrm{x}$ L. japonica. J Exp Bot 47:1509-1517

Ellenberg H (1996) Vegetation Mitteleuropas mit den Alpen in ökologischer, dynamischer und historischer Sicht. Ulmer, Stuttgart, pp 1093

Fraser AI, Gardiner JBH (1967) Rooting and stability in Sitka Spruce. For Commission Bull 40:1-28

Gardiner BA, Peltola H, Kellomäki S (2000) Comparison of two models for predicting the critical wind speeds required to damage coniferous trees. Ecol Model 129:1-23

Kollman FPP, Côté WA (1968) Principles of wood science and technology. I, Solid wood. Springer-Verlag, pp 502

Meteoschweiz (2004) Messstation Davos. http://www.meteoschweiz.ch/- de/Klima/Klimapublikationen/IndexKlimapublikationen.shtml. 
Milne R (1991) Dynamics of swaying of Picea sitchensis. Tree Physiol 9:383-399

Milne R, Blackburn P (1989) The elasticity and vertical distribution of stress within stems of Picea sitchensis. Tree Physiol 5:195-205

Moore JR (2000) Differences in maximum resistive bending moments of Pinus radiata trees grown on a range of soil types. Forest Ecol Manag 135:63-71

Neild SA, Wood CJ (1999) Estimating stem and rootanchorage flexibility in trees. Tree Physiol 19:141-151

Nicoll BC, Achim A, Mochen S, Gardiner BA (2005) Does steep terrain influence tree stability? A field investigation. Can J For Res 35:2360-2367

Peltola H, Kellomäki S, Väisänen H, PIV (1999) A mechanistic model for assessing the risk of wind and snow damage to single trees and stands of Scots pine, Norway Spruce and Birch. Can J For Res 29:647-661
Peltola H, Kellomäki S, Hassinen A, Granander M (2000) Mechanical stability of Scots pine, Norway spruce and Birch: an analysis of tree-pulling experiments in Finland. Forest Ecol Manag 135:143-153

Saunderson SET, England AH, Baker CJ (1999) A dynamic model of the behaviour of Sitka Spruce in high winds. J Theor Biol 200:249-259

Stokes A, Berthier S, Nadhezdhina NJC, Loustau D (2000) Sap flow in trees is influenced by stem movement. In: Spatz HZ, Speck T (eds) Plant biomechanics 2000: proceedings of the 3rd plant biomechanics conference freiburg-badenweiler, 27 August-2 September, 2000. Stuttgart, Thieme, pp 272-277

Yang YB, Yang YT, Su HH (2004) Behavior of the tree branches, trunk, and root anchorage by nonlinear finite element analysis. Adv Struct Eng 7:1-14 